\title{
BUBBLE COALESGENGE IN ICE AS A TOOL FOR THE STUDY OF ITS DEFORMATION HISTORY
}

\author{
By J. Weertman* \\ (U.S. Army Cold Regions Research and Engineering Laboratory, Hanover, \\ New Hampshire 03755, U.S.A.)
}

\begin{abstract}
An analysis is made of the rate of bubble coalescence in an ice mass that is deforming. A total strain of at least 8 is required before appreciable coalescence occurs. The analysis has been applied to deforming ice shelves and ice sheets. No appreciable coalescence is expected in ice shelves but coalescence should occur in ice sheets (or glaciers) if the shear strain-rate at the bottom surface is of the order of $0.075 /$ year or larger. Measurements of bubble concentration are capable of setting limits on paleo-strain-rates of the present ice sheets. Bubble migration down temperature gradients presents complications to the study of bubble coalescence.

RÉsumÉ. La coalescence de bulles d'air dans la glace utilisée comme moyen d'étude de l'histoire de sa déformation. On a procédé à l'analyse de la vitesse de coalescence des bulles d'air d'une masse de glace soumise à déformation. Une deformation totale d'au moins 8 est nécessaire avant qu'une coalescence sensible aparaisse. Cette analyse a été appliquée aux indlandsis et glaciers en train de se déformer. Aucune appréciable coalescence n'est attendue dans les ice shelves, mais la coalescence apparaîtra dans des indlandsis (ou glaciers) si la valeur de la vitesse de cisaillement à la surface du socle rocheux est de l'ordre de $0,075 /$ an ou plus supérieur. Des mesures de concentration de bulles d'air sont capable d'indiquer les limites des valeurs des paléo-vitesses de cisaillement des indlandsis actuels. La migration des bulles à des gradients de température présente des complications pour l'étude de la coalescence des bulles.

Zusammenfassung. Der Zusammenschluss von Blasen im Eis als Mittel zum Studium seiner Deformationsgeschichte. Die Geschwindigkeit der Blasenzusammenschlüsse in einer sich verformenden Eismasse wird untersucht. Bevor ein wahrnehmbarer Zusammenschluss eintritt, ist eine Gesamtverzerrung von mindestens 8 erforderlich. Die Untersuchung wurde auf sich verformende Eisschelfe und Eiskalotten angewandt. In Eisschelfen wird kein merklicher Zusammenschluss erwartet; in Eiskalotten (oder Gletschern) sollte er jedoch eintreten, wenn die Schergeschwindigkeit am Untergrund den Wert 0,075 pro Jahr oder grösser erreicht. Messungen der Blasenkonzentration erlauben die Bestimmung von früheren Grenzschergeschwindigkeiten in derzeitigen Eiskalotten. Die Blasenwanderung entlang von Temperaturgradienten erschwert das Studium des Blasenzusammenschlusses.
\end{abstract}

\section{INTRODUCTION}

If ice containing entrapped gas bubbles is deformed to large strains it is inevitable that the deformation will lead to coalescence of the bubbles. The coalescence process is illustrated in Figure I. Figure ra depicts two bubbles whose separation in the vertical direction is less than the diameter of the bubbles. Large shear deformation causes the two bubbles to collide, as shown in Figure $\mathrm{rb}$. The phenomena of surface tension and diffusion have turned the coalesced bubbles in Figure ic into a spherical shape.

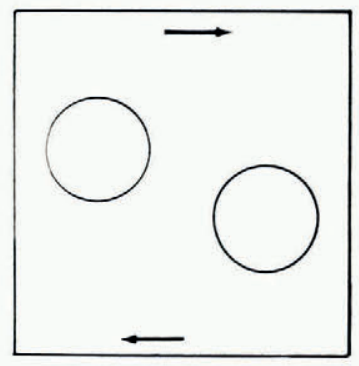

a.

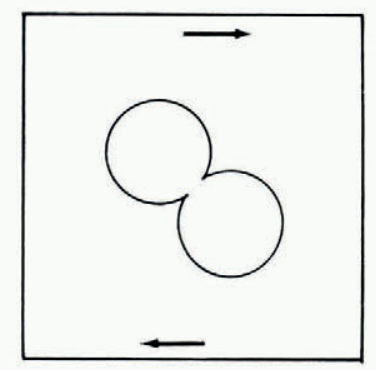

b.

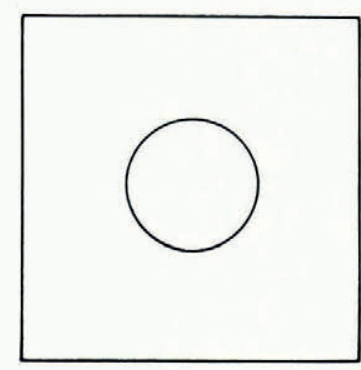

c.

Fig. I. Bubble coalescence. (a) Before meeting. Upper bubble moves to right with respect to lower bubble. (b) Just after meeting. (c) After spheroidization of coalesced bubbles

* Permanent address: Materials Science Department and Geology Department, Northwestern University, Evanston, Illinois 60201, U.S.A. 
The degree of coalescence of an initially random dispersion of gas bubbles in ice indicates a measure of the total amount of plastic deformation the ice has suffered. Therefore, an analysis of bubble coalescence offers a source of information concerning the deformation of ice which is particularly valuable in the study of the total deformation of ice in glaciers and ice sheets.

In this paper we will derive the equation for the rate of bubble coalescence. The change in bubble size caused by the application of hydrostatic pressure will be taken into account. We also will examine the complications arising from the fact that bubbles can migrate down temperature gradients. It is assumed throughout this paper that the processes causing spheroidization of the bubbles act so fast that the bubbles can always be considered to be spheres.

\section{THEORY}

Consider again Figure I. Let $a$ be the average value of the radius of the bubbles at any given instant in time. Let $C$ be the number of bubbles per unit volume and let $V$ represent the total volume of the bubbles per unit volume. Thus $V=(4 \pi / 3) C a^{3}$. Let $\dot{\epsilon}$ be the plastic (shear) strain-rate. (If $u$ is the horizontal ice velocity and the vertical velocity is zero then $\dot{\epsilon}=\partial u / \partial y$.)

The average velocity of approach of two bubbles that can collide is of the order of $\dot{\epsilon} a$. The rate of collision of any one bubble can be found as follows: Let $u, v$ and $w$ be the velocity components in the $x, y$ and $z$ directions respectively. Consider the case where $u \neq 0$ and $v=w=0$. Let $r=\left(y^{2}+z^{2}\right)^{\frac{1}{2}}$ be the separation of the centers of two bubbles when projected on a plane perpendicular to the $x$ axis. Let $\theta$ be the angle defined by $\sin \theta=y / r$. Let the origin be taken to be at the center of one of the spheres. Two bubbles can collide only if $r \leqslant 2 a$. The rate of approach of two bubbles is $\dot{\boldsymbol{\epsilon}} y=\dot{\epsilon} r \sin \theta$. Therefore the rate of collision of one bubble with the others is $\int_{0}^{\pi / 2} \int_{0}^{2 a} 4 \dot{\epsilon} C r^{2} \sin \theta \mathrm{d} r \mathrm{~d} \theta$ which integrates to give the rate of collision as $\left(3^{2 / 3}\right) C \dot{\epsilon} a^{3}$. The concentration $C$ of bubbles decreases each time two bubbles coalesce. The time rate of decrease $\mathrm{d} C / \mathrm{d} t$ is simply

$$
\mathrm{d} C / \mathrm{d} t=-(\mathrm{r} 6 / 3) C^{2} \dot{\epsilon} a^{3}=-(4 / \pi) V C \dot{\epsilon} .
$$

If the hydrostatic pressure $P$ is constant so that $V$ is a constant the concentration decays exponentially with total strain according to the equation

$$
C=C_{\mathrm{o}} \exp \left(-\epsilon / \epsilon_{\mathrm{o}}\right)
$$
where $C_{0}$ is the initial bubble concentration, $\epsilon$ is the total strain $\left(\epsilon=\int_{0}^{t} \dot{\epsilon} \mathrm{d} t\right)$ at a given
instant in time, and $\epsilon_{0}$ is the constant

$$
\epsilon_{0}=\pi / 4 V .
$$

The characteristic decay strain $\epsilon_{0}$ is a large number. If $V=0 . \mathrm{I}, \epsilon_{0}=8$, which is a total shear strain of 800 per cent. The coalescence effect is important only for total plastic strains of this order of magnitude or larger.

\section{Application to Ige Sheets and Ice Shelves}

The coalescence effect may be used to determine the total plastic deformation of ice sheets, ice shelves and glaciers. Air bubbles are entrapped in the ice of such ice masses during the sintering of the firn layer. The analysis of the rate of coalescence is complicated by the fact that the hydrostatic pressure does not remain constant. The volume fraction $V$ of Equation (I) should be replaced* by $V_{\mathrm{o}} P_{\mathrm{o}} / P$, where $V_{\mathrm{o}}$ is the fractional volume of the bubbles

\footnotetext{
* Langway (1958) has measured the pressure within ice bubbles in ice taken from cores of the bore hole in the Greenland ice sheet at "Site 2". The deepest core came from a depth of $360 \mathrm{~m}$. He showed that the pressure in the bubbles was always 3 to 4 bars smaller than the sum of the overburden pressure plus the atmospheric pressure. $\mathrm{He}$ found that the pores closed off from each other at a depth corresponding to an overburden pressure of the order of 3 to 4 bars. These observations can be taken into account in the equations of this paper by redefining $h^{\star}$ to be $h^{\star}=y_{0}+p^{\star} / \rho g$. According to Langway's data the product $V_{\mathrm{o}}\left(h^{\star}-y_{\mathrm{o}}\right) \approx \mathrm{r} .0 \mathrm{~m}$.

Gow (1968) has shown that the lag of 3 to 4 bars in the pressure of the gas bubbles is reduced to I bar at a depth of $200 \mathrm{~m}$ in the case of cores taken from a bore hole at "Byrd" station in Antarctica.
} 
at the instant the pores in the firn layer close off from each other, and $P_{0}$ is the overburden pressure plus the atmospheric pressure $p^{\star}$ at the instant this process occurs. If $y$ represent the vertical distance of an ice particle above the bottom of an ice mass, the hydrostatic pressure $p$ acting on the ice particle is $p^{\star}+\rho g(h-y)$, where $\rho$ is the ice density, $g$ is the gravitational acceleration, and $h$ is the total ice thickness. Thus $V$ is given by

$$
\begin{aligned}
V & =V_{\mathrm{o}}\left[\left(h-y_{\mathrm{o}}\right)+\left(p^{\star} / \rho g\right)\right] /\left[(h-y)+\left(p^{\star} / \rho g\right)\right] \\
& =V_{\mathrm{o}}\left(h^{\star}-y_{\mathrm{o}}\right) /\left(h^{\star}-y\right)
\end{aligned}
$$

where $\left(h-y_{0}\right)$ is the depth at which pores close off from each other in the firn layer and $h^{\star}=h+p^{\star} / \rho g$.

$=h+p^{\star} / \rho g$.
Along the flow path of an ice particle the integral $\int_{0}^{t} S \mathrm{~d} t$, where $S$ is the ice velocity in the vertical direction, is equal to $(h-y)$. Here the time $t$ is measured from the instant the ice particle was deposited at the upper surface. Along the flow path $\mathrm{d} y / \mathrm{d} t=S$. With the use of this relationship Equation (I) can be rewritten as

$$
\mathrm{d} C / \mathrm{d} y=-(4 / \pi) \dot{\epsilon} V_{0} C\left(h^{\star}-y_{0}\right) / S\left(h^{\star}-y\right)
$$

where the derivative on the left-hand side of this equation is understood to be taken along the flow path of the ice particle. If $C$ is independent of, or only weakly dependent on, the horizontal distance this derivative is an ordinary derivative.

\section{Ice shelf}

It will be shown now that coalescence effects are unimportant in the case of floating ice shelves. Consider an ice shelf on which ice is neither being melted from nor frozen to the bottom surface. Let $A$ be the accumulation rate on the top surface. Then $S=-A y / h$. The longitudinal strain-rate is $A / h$ for an ice shelf restricted to motion in only one horizontal direction. The effective shear strain-rate is $\dot{\epsilon}=2 A / h$. Inserting these last two expressions into Equation (5) and integrating gives

$$
\ln \left(C_{\mathrm{o}} / C\right)=\left\{2 V_{\mathrm{o}}\left(h^{\star}-y_{\mathrm{o}}\right) / \pi h^{\star}\right\} \ln \left\{\left(h^{\star}-y\right) y_{\mathrm{o}} / y\left(h^{\star}-y_{\mathrm{o}}\right)\right\} .
$$

This equation predicts that $C=C_{0}$ everywhere except in an infinitesimally thin layer at the bottom surface of the ice shelf.

We can arrive at this result in another way. In the previous section it was seen that coalescence effects are unimportant until the total shear strain is at least of the order of 8 . At a time $t$ after deposition an ice particle in an ice shelf has undergone a total shear strain $(A / h) t$. At time $t$ the same particle has descended to the vertical distance $y$ given by $t=(h / A) \ln (h / y)$. The value of $y$ at which $(A / h) t=8$ is $h \exp (-8)$. We can conclude that coalescence of bubbles caused by longitudinal strain-rates in ice shelves, as well as in glaciers and ice sheets, is negligible.

\section{Ice sheet}

Consider next the coalescence of bubbles within an ice sheet at a point well removed from its center. Assume again that no melting or freezing occurs at the bottom surface. The ice velocity $S$ in the vertical direction is approximately $-A y / h$. The shear stress $\sigma$ at $y$ is approximately $\rho g(h-y) \alpha$, where $\alpha$ is the slope of the upper surface. According to Glen (1955) the creep rate is proportional to $\sigma^{n}$, where $n$ is a constant whose value lies in the range of 3 to 4 . If $\dot{\epsilon}_{\mathrm{o}}$ is the shear creep rate at the bottom surface $\dot{\epsilon}=\dot{\epsilon}_{\mathrm{o}}[(h-y) / h]^{n}$. Inserting this expression for $\dot{\epsilon}$ and the previous expression for $S$ into Equation (5) and integrating gives

$$
\ln \left(C_{\mathrm{o}} / C\right)=\left(4 V_{\mathrm{o}}\left[h^{\star}-y_{0}\right] \dot{\epsilon}_{\mathrm{o}} / \pi A\right)\left(h / h^{\star}\right) \int_{y}^{y_{0}}\left[(\mathrm{I}-y / h)^{n} / y\left(\mathrm{I}-y / h^{\star}\right)\right] \mathrm{d} y .
$$

If terms in $\left(h^{\star}-h\right) / h$ or higher are dropped this equation reduces, for $n=3$, to

$$
\ln \left(C_{\mathrm{o}} / C\right)=\left(4 V_{\mathrm{o}}\left[h^{\star}-y_{\mathrm{o}}\right] \dot{\epsilon}_{\mathrm{o}} / \pi A\right)\left[\ln \left(y_{\mathrm{o}} / y\right)-(2 / h)\left(y_{\mathrm{o}}-y\right)+\left(\mathrm{I} / 2 h^{2}\right)\left(y_{\mathrm{o}}^{2}-y^{2}\right)\right] .
$$


Figure 2 shows plots of $C / C_{0}$ versus $y / h$ for the case in which $y_{0}=h ; V_{0}\left(h^{\star}-y_{0}\right)=\mathrm{I} \mathrm{m}$ (obtained from data of Langway (1958));A=0.35 m/year; and $\epsilon_{0}$ has each of the following values: $0.75 /$ year, $0.075 /$ year, and $0.0075 /$ year.

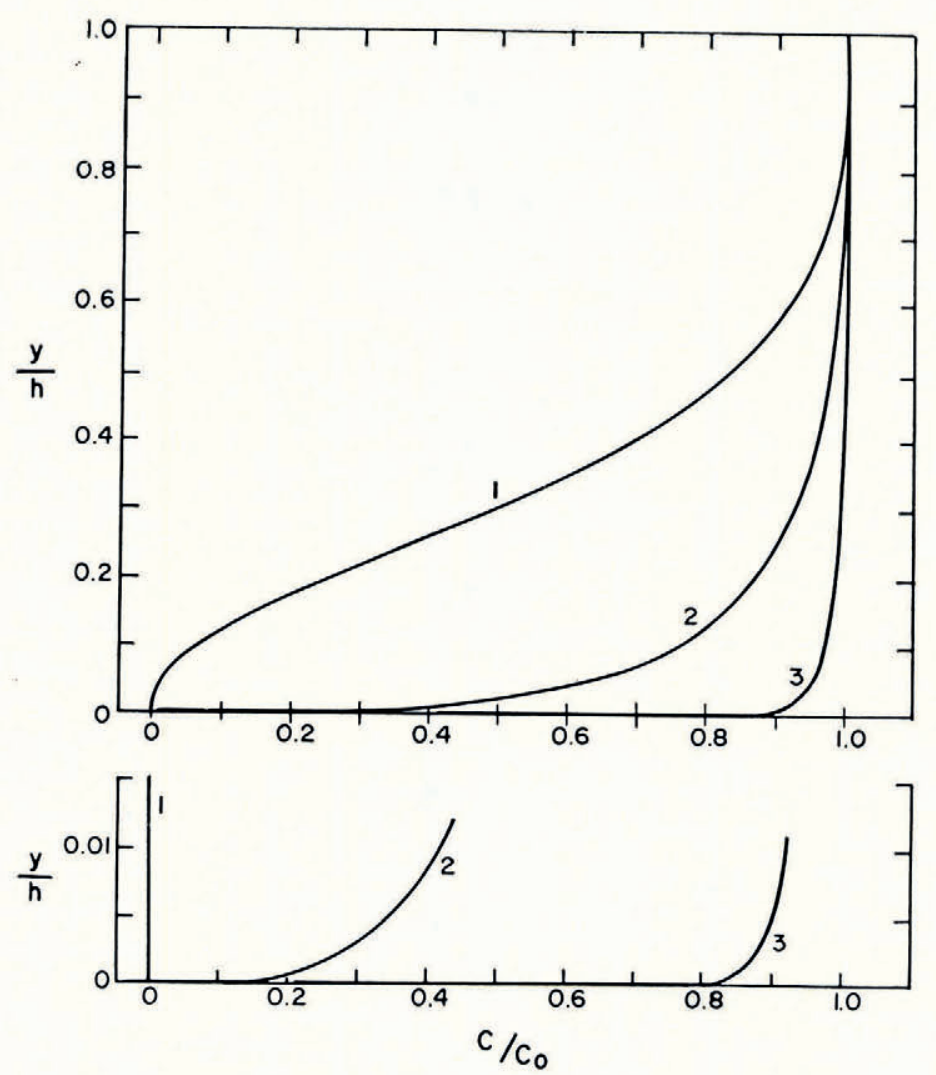

Fig. 2. Normalized bubble concentration $\left(C / C_{0}\right)$ versus normalized distance from bottom surface $(y / h)$. Curve I for strain-rate $\dot{\epsilon}_{0}=0.75 /$ year; Curve 2 for $\dot{\epsilon}_{0}=0.075 /$ year; and Curve 3 for $\dot{\epsilon}_{0}=0.0075 /$ year

It can be seen from this figure that if the concentration of pores is to be reduced significantly the strain-rate $\dot{\epsilon}_{0}$ must be of the order of 0.075 /year or larger. The strain-rate $\dot{\epsilon}_{0}$ of an ice sheet or glacier that does not slide over its bed can be estimated from the horizontal surface velocity and the ice thickness. It is approximately equal to $(n+\mathrm{I}) u / h$, where $u$ is the horizontal ice velocity measured at the upper ice surface. Thus, the ice velocity must be at least of the order of (o.075/year) $h /(n+\mathrm{I})$ before the bubble concentration changes by a measurable amount. For ice thicknesses of 500, I 000 , i 500 and $2000 \mathrm{~m}$ the horizontal ice velocity must be at least of the order of $9,18,25$ and $36 \mathrm{~m} /$ year, respectively.

The degree of bubble coalescence offers a sensitive means for setting limits on the paleostrain-rates of existent ice sheets. For example, it is estimated that $\dot{\epsilon}_{0}$ for the Greenland ice sheet at "Camp Century" (Weertman, I968) is of the order of o.or5/year. (The surface velocity there is about $3.3 \mathrm{~m} /$ year and the ice thickness is almost $1400 \mathrm{~m}$.) Thus, according to Figure 2 virtually no bubble coalescence should have taken place. However, if over the past 5000 to 10000 years the velocity of ice at "Camp Century" were actually an order of magnitude faster than it is now appreciable bubble coalescence should have occurred. Measurements of the bubble concentration in cores taken from the "Camp Century" bore hole thus will be 
able to set an upper limit on past ice velocities. (From a study (Weertman, I968) of the temperature profile of the "Camp Century" bore hole it was concluded that past ice velocities could not have been appreciably greater than the present-day ice velocity.)

\section{Effect of bubble migration}

The preceding calculations were made under the assumption that the bubbles do not move with respect to the ice matrix. This assumption is not correct. Hoekstra and others ( $1965[a],[b])$ have shown that small brine pockets migrate down temperature gradients in cold ice. (The pockets move from colder to warmer temperature regions.) Hoekstra and Miller ( 1965 ) showed that small inclusions surrounded by a thin water film also drift in a temperature gradient. Air bubbles in cold ice will migrate in the presence of temperature gradients. This fact has been shown theoretically by Shreve (1967) and experimentally by Stehle (1967). Shreve's equation leads to the prediction that air bubbles near the bottom of the Greenland ice sheet at "Camp Century" (the temperature gradient there is $1.77 \times 10^{-4}$ $\mathrm{deg} / \mathrm{cm}$ (Hansen and Langway, I 966 ) and the pressure is of the order of 140 bars) will migrate downwards at velocities of the order of ${ }_{10} 0^{-6} \mathrm{~cm} /$ year. This velocity is such an extremely slow one that it could not lead to any significant modification of the bubble density that was calculated in the last section.

\section{SUMMARY}

The analysis of this paper shows that bubble concentrations within an ice mass are potential sources of information concerning the total deformation suffered by the ice mass. The analysis was made under the assumption that no melting or freezing occurs at the bottom ice surface. The generalization of the results to cover the case of melting or freezing is obvious. Essential to the analysis is the assumption that the processes causing spheroidization of the bubbles act so fast that bubbles are never elongated or flattened by the deformation. At very fast strain-rates this assumption obviously will break down.

\section{ACKNOWLEDGEMENTS}

I would like to thank Mr A. J. Gow, Mr L. B. Hansen and Dr P. Hoekstra for fruitful discussions.

MS. received ${ }_{13}$ October ${ }_{1967}$

\section{REFERENCES}

Glen, J. W. 1955. The creep of polycrystalline ice. Proceedings of the Royal Society, Ser. A, Vol. 228, No. 1175 , p. $5^{1} 9^{-38}$.

Gow, A. J. I968. Bubbles and bubble pressures in Antarctic glacier ice. Journal of Glaciology, Vol. 7, No. 50, p. $167-82$.

Hansen, B. L., and Langway, C. C., jr. 1966. Deep core drilling in ice and core analysis at Camp Century, Greenland, 1961-1966. Antarctic Journal of the United States, Vol. 1, No. 5, p. 207-08.

Hoekstra, P., and Miller, R. D. 1965 . The movement of water in a film between glass and ice. U.S. Cold Regions Research and Engineering Laboratory. Research Report ${ }_{1} 53$.

Hoekstra, P., and others. $1965[\mathrm{a}]$. The migration of liquid inclusions in single ice crystals, by P. Hoekstra, T. E. Osterkamp and W. F. Weeks. Journal of Geophysical Research, Vol. 70, No. 20, p. 5035-4I.

Hoekstra, P., and others. $1965[\mathrm{~b}]$. Migration of liquid inclusions in single ice crystals, by P. Hoekstra, T. E. Osterkamp and W. F. Weeks. U.S. Cold Regions Research and Engineering Laboratory. Research Report 183.

Langway, C. C., jr. 1958. Bubble pressures in Greenland glacier ice. Union Géodésique et Géophysique Internationale. Association Internationale d'Hydrologie Scientifique. Symposium de Chamonix, I6-24 sept. 1958, p. 336-49.

Shreve, R. L. 1967 . Migration of air bubbles, vapor figures, and brine pockets in ice under a temperature gradient. Journal of Geophysical Research, Vol. 72, No. 16, p. 4093-100.

Stehle, N. S. 1967 . Migration of bubbles in ice under a temperature gradient. (In Oura, H., ed. Physics of snow and ice: international conference on low temperature science. . . 1966. . . Proceedings, Vol. I, Pt. I. [Sapporo], Institute of Low Temperature Science, Hokkaido University, p. 219-32.)

Weertman, J. 1968. Comparison between measured and theoretical temperature profiles of the Camp Century, Greenland, bore hole. Journal of Geophysical Research, Vol. 73, No. 8, p. 2691-700. 